E3S Web of Conferences 1, 40005 (2013)

DOI: $10.1051 / \mathrm{e} 3$ sconf/20130140005

(C) Owned by the authors, published by EDP Sciences, 2013

\title{
Exposure assessment to heavy metals in general population in a polluted area through biological monitoring
}

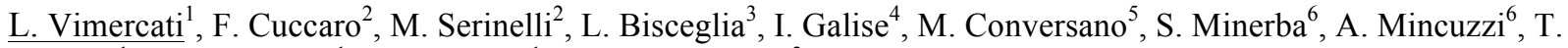 \\ Martino $^{1}$, M. A. Storelli ${ }^{1}$, T. Gagliardi ${ }^{1}$ and G. Assennato ${ }^{2}$ \\ ${ }^{1}$ Interdisciplinary Department of Medicine - Section of Occupational Medicine "B.Ramazzini" - University of Bari \\ “Aldo Moro", Bari, Italy. E-mail: 1.vimercati@medlav.uniba.it \\ ${ }^{2}$ ARPA Puglia, Bari, Italy. E-mail: f.cuccaro@arpa.puglia.it \\ ${ }^{3}$ ARES Puglia, Bari, Italy. E-mail: 1.bisceglia@arespuglia.it \\ ${ }^{4}$ Apulia Cancer Registry, Bari, Italy. E-mail: ida.galise@oncologico.bari.it \\ ${ }^{5}$ Department of Prevention - Health Local Organization, Taranto, Italy. E-mail: dip.conversano@libero.it \\ ${ }^{6}$ Statistics - Epidemiology Unit - Health Local Organization, Taranto, Italy. E-mail: aldominerba@libero.it
}

\begin{abstract}
In polluted areas, a major issue is the correct assessment of the exposure of general population to industrial pollutants. The objectives were: to evaluate the exposure to heavy metals emitted from the industrial area of Taranto; to correlate biological monitoring data with environmental data, in order to clarify the impact of industrial pollution in terms of internal dose. A cross sectional study has been designed to measure levels of urinary arsenic, lead, cadmium, chromium, manganese in 300 inhabitants of Taranto, Statte and Laterza. Adult subjects have been selected by a two-stage random stratified sampling. Results are based on 272 subjects (131 men and 141 women). The observed concentrations of metals in the whole study population are overall high. The median values for lead $(7.4 \mu \mathrm{g} / \mathrm{l})$ and chromium $(0.4 \mu \mathrm{g} / \mathrm{l})$ are higher than $95^{\circ}$ percentile of the range of reference values. For manganese and arsenic the $95^{\circ}$ percentile of concentration in the whole study population is higher than the $95^{\circ}$ percentile of the range of reference values. Concentrations of mercury in the whole study population are comparable to reference.
\end{abstract}

Key words: heavy metals, environmental exposure, biological monitoring, cross sectional study

\section{Introduction}

Taranto is a Southern Italy town on the Ionian sea, where many sources of air pollutants are located nearby the urban area. Industrial area includes a large integrated cycle steel factory, a refinery and a cement factory. In the province of Taranto an area at "high risk of environmental crisis", that includes the municipalities of Taranto, Statte, Massafra, Montemesola, Crispiano, has been identified by Italian Ministry of Environment. A major issue in polluted areas is the correct assessment of the exposure of general population to industrial pollutants.

The objectives were: to evaluate the exposure to heavy metals emitted from the industrial area of Taranto and to compare the exposure between subjects living in the "polluted area" and in a "non-polluted area"; to correlate biological monitoring data with environmental data, in order to clarify the impact of industrial pollution in terms of internal dose.

\section{Materials and Methods}

A cross sectional study has been designed to measure levels of urinary arsenic (iAs+MMA+DMA), lead $(\mathrm{Pb})$, mercury $(\mathrm{Hg})$, chromium $(\mathrm{Cr})$, manganese $(\mathrm{Mn})$ in 300 subjects resident, aged 19-65 years old, in Taranto, in Statte (a small town close to the industrial area) and Laterza, a rural town considered the "blank" site, from January 2010 to April 2012. Moreover, municipality of Taranto was disaggregated into three areas: the working class neighbourhood "Paolo VI", the closest to industrial area neighborhood "Tamburi - Old Town" and "New Town", that includes the rest of the city.

Adult subjects have been selected by a two-stage random sampling, stratified by age and gender and 30 subjects have been enrolled as volunteers. Each subject in the study has been asked to sign the informed consent 
form and has been administered by qualified health personnel a structured standardized questionnaire to collect personal data in order to control for potential confounders such as smoking habits, water consumption, presence of fireplace at home and use of pesticides or paints. The analysis of urinary samples has been performed by the Industrial Toxicology Laboratory of the Occupational Medicine Section "B. Ramazzini" of the University of Bari using Atomic Absorption Spectrophotometer. For the determination of As, hydride procedure with generation of arsine was employed; for $\mathrm{Hg}$ determination, the cold vapor technique and for the other metals the graphite furnace method.

Comparisons among groups have been performed by non-parametric methods (Wilcoxon rank sum test and Kruskall Wallis test). A p-value $\leq 0.05$ was considered significant. Statistical analysis was conducted using SAS (v. 9.0) and STATA (v. 11).

\section{Results and Discussion}

Results are based on 272 subjects, including 30 volunteers (131 men and 141 women) (mean age $\pm \mathrm{SD}=$ $43.1 \pm 13.0)$.

The Table 1 reports subjects's residential distribution.

Table 1. Residential distribution of the subjects.

\begin{tabular}{lrr}
\hline City & n. & \% \\
\hline Laterza & 38 & 14 \\
Statte & 55 & 20.2 \\
Taranto & 179 & 65.8 \\
Total & $\mathbf{2 7 2}$ & $\mathbf{1 0 0}$ \\
Neighboorhood in Taranto & & \\
New Town & 90 & 33.1 \\
Tamburi Old Town & 50 & 18.4 \\
Paolo VI & 39 & 14.3 \\
\hline
\end{tabular}

The Table 2 shows descriptive statistics of metals concentrations in urine and the reference range $\left(5^{\circ}-95^{\circ}\right.$ percentile in non occupational exposed population) provided by Italian Society of Reference Values (SIVR). It is notable that for $\mathrm{Pb}, \mathrm{Cr}, \mathrm{Mn}$ and $\mathrm{As}$, the $95^{\circ}$ percentile in study population was higher than the $95^{\circ}$ percentile in SIVR reference values, and for $\mathrm{Pb}$ and $\mathrm{Cr}$ also the median value was higher than the $95^{\circ}$ percentile of reference value. Just for $\mathrm{Hg}$ the range in study population was comparable to SIVR reference range.

Arsenic: median value is higher in men $(4.1 \mu \mathrm{g} / \mathrm{l})$ than in women $(3.8 \mu \mathrm{g} / \mathrm{l})$; in the $15-19$ years age-group $(7.4 \mu \mathrm{g} / \mathrm{l})$; in smokers $(4.2 \mu \mathrm{g} / \mathrm{l})$ than in non-smokers $(3.8$ $\mu \mathrm{g} / \mathrm{l})$; between consumers of mineral water $(4.2 \mu \mathrm{g} / \mathrm{l})$ than aqueduct water $(3.6 \mu \mathrm{g} / 1)$; between who ate fish or crustacean the day before the interview $(4.75 \mu \mathrm{g} / \mathrm{l} \mathrm{vs} 3.8$ $\mu \mathrm{g} / 1$ and $9.8 \mu \mathrm{g} / 1 \mathrm{vs} 3.8 \mu \mathrm{g} / \mathrm{l}$ respectively) or mollusc two days before the interview $(8.3 \mu \mathrm{g} / 1$ vs $3.8 \mu \mathrm{g} / \mathrm{l})$. The median concentrations disaggregated by city are: $8.8 \mu \mathrm{g} / 1$ in Statte, $3.8 \mu \mathrm{g} / 1$ in Taranto and $2.75 \mu \mathrm{g} / 1$ in Laterza. Among the neighbourhoods of Taranto the highest median concentration was observed in Tamburi-Old Town $(4.6 \mu \mathrm{g} / \mathrm{l}$ vs $3.8 \mu \mathrm{g} / \mathrm{l}$ in New Town and $2.7 \mu \mathrm{g} / \mathrm{l}$ in Paolo VI). Differences in urinary concentrations are statistically significant by city and among Taranto neighbourhoods, and in subjects which consumed crustacean and mollusc within two days prior to the collection of urinary samples.

Chromium: median urinary levels of chromium are similar in both sexes, by age-groups, between smokers and no-smokers and between consumers of waters. The median concentrations by city are: $0.5 \mu \mathrm{g} / 1$ in Statte, 0.3 $\mu \mathrm{g} / \mathrm{l}$ in Taranto and $0.35 \mu \mathrm{g} / \mathrm{l}$ in Laterza with a statistically significant difference. Among the neighbourhoods of Taranto the highest median concentration was observed in Paolo VI $(0.4 \mu \mathrm{g} / \mathrm{l}$ vs $0.3 \mu \mathrm{g} / 1$ in the others) but differences are not statistically significant.

Manganese: median values are higher in women than in men $(1.4 \mu \mathrm{g} / 1$ vs. $1.2 \mu \mathrm{g} / \mathrm{l})$, in the $25-29$ years age-group $(2.0 \mu \mathrm{g} / \mathrm{l})$, between smokers and no-smokers $(1.4 \mu \mathrm{g} / 1 \mathrm{vs} .1 .2 \mu \mathrm{g} / 1)$. The median concentrations by city are: $0.5 \mu \mathrm{g} / 1$ in Statte, $1.6 \mu \mathrm{g} / 1$ in Taranto and $2.4 \mu \mathrm{g} / 1$ in Laterza and intergroup difference is statistically significant. Among the neighbourhoods of Taranto the highest median concentration was in Paolo VI $(2.2 \mu \mathrm{g} / 1$ vs $1.6 \mu \mathrm{g} / 1$ in New Town and $0.75 \mu \mathrm{g} / 1$ in Tamburi-Old Town) with a statistically significant differences.

Mercury: median urinary levels of mercury are higher in men than in women $(1.0 \mu \mathrm{g} / \mathrm{l} \mathrm{vs} 0.8 \mu \mathrm{g} / \mathrm{l})$, in the $40-44$ years age-group $(1.3 \mu \mathrm{g} / \mathrm{l})$, in smokers $(1.1 \mu \mathrm{g} / \mathrm{l} \mathrm{vs}$. $0.8 \mu \mathrm{g} / \mathrm{l})$. The median concentrations by city are: $1.8 \mu \mathrm{g} / 1$ in Statte, $0.7 \mu \mathrm{g} / 1$ in Taranto and $0.8 \mu \mathrm{g} / 1$ in Laterza and intergroup difference is statistically significant. Median concentrations are significantly different among the neighbourhoods of the Taranto $(0.9 \mu \mathrm{g} / 1$ in Tamburi-Old Town, $0.8 \mu \mathrm{g} / \mathrm{l}$ in Paolo VI and $0.6 \mu \mathrm{g} / \mathrm{l}$ in New Town ).

Differences in median urinary concentration are statistically significant by age and in subjects who had consumed crustacean $48-72$ hours prior to the collection of urinary samples.

Lead: median concentrations are similar in both sexes $(7.3 \mu \mathrm{g} / \mathrm{l}$ in men and $7.5 \mu \mathrm{g} / \mathrm{l}$ in women), between consumers of mineral or acqueduct water $(7.5 \mu \mathrm{g} / 1 \mathrm{vs}$. $7.4 \mu \mathrm{g} / 1)$. Median values are higher in the 55-59 years age-group $(6.2 \mu \mathrm{g} / \mathrm{l})$ than in remaining age-groups. The concentrations by city are: $12.1 \mu \mathrm{g} / 1$ in Statte, $7.3 \mu \mathrm{g} / 1$ in Taranto and $4.2 \mu \mathrm{g} / 1$ in Laterza and this difference is statistically significant. Among the neighbourhoods of Taranto the highest median concentration was observed in New Town $(7.4 \mu \mathrm{g} / 1$ vs $7.3 \mu \mathrm{g} / 1$ in Tamburi-Old Town and $6.9 \mu \mathrm{g} / \mathrm{l}$ in Paolo VI).

Differences in median urinary concentrations are statistically significant in subjects which ate fish 72 hours $(8 \mu \mathrm{g} / 1$ vs $7.2 \mu \mathrm{g} / 1)$ prior to the collection of urinary sample 
Table 2. Descriptive statistics of metals concentrations measured in the study population

\begin{tabular}{|c|c|c|c|c|c|}
\hline & As $\mu \mathrm{g} / 1$ & $\mathrm{Cr} \mu \mathrm{g} / 1$ & $\mathrm{Mn} \mu \mathrm{g} / 1$ & $\mathrm{Hg} \mu \mathrm{g} / \mathrm{l}$ & $\mathrm{Pb} \mu \mathrm{g} / \mathrm{l}$ \\
\hline mean & 6.2 & 0.5 & 2.7 & 1.4 & 9.5 \\
\hline DS & 8.7 & 0.5 & 6.8 & 1.6 & 6.9 \\
\hline $\min$ & 0.3 & 0.1 & 0.2 & 0.1 & 0.8 \\
\hline p5 & 1.5 & 0.1 & 0.3 & 0.2 & 2.0 \\
\hline $\mathrm{p} 25$ & 2.7 & 0.2 & 0.6 & 0.5 & 4.6 \\
\hline p50 & 3.9 & 0.4 & 1.3 & 0.8 & 7.4 \\
\hline $\mathrm{p} 75$ & 6.4 & 0.6 & 2.5 & 1.5 & 13.1 \\
\hline p95 & 16.8 & 1.3 & 8.7 & 4.5 & 24.3 \\
\hline $\max$ & 92.4 & 5.1 & 90.4 & 12.2 & 32.4 \\
\hline $\mathrm{n}$. & 272 & 272 & 272 & 272 & 270 \\
\hline reference values & $2.0-15$ & $0.05-0.32$ & $0.2-4.0$ & $0.1-4.5$ & $0.1-4.5$ \\
\hline
\end{tabular}

\section{Conclusions}

Results from biological monitoring can allow to address the issue of preventing harmful effects of environmental factors and they can be related with environmental emission data, like those provided by EMEP (European Monitoring and Evaluation Programme). For the whole province of Taranto the value of emissions of $\mathrm{Pb}$ into the atmosphere in 2009 was 38 tons, one the highest in Europe, and the emissions of $\mathrm{Hg}$ in the same year was $510 \mathrm{Kg}$. There are no available data concerning emissions of the other metals.

The observed concentrations of metals in the whole study population are overall high. The median values for $\mathrm{Pb}(7.4 \mu \mathrm{g} / \mathrm{l})$ and $\mathrm{Cr}(0.4 \mu \mathrm{g} / \mathrm{l})$ are higher than the $95^{\circ}$ percentile of the range of reference values provided by SIVR (3.5 and 0.32 respectively). For both the metals the highest median concentration has been found in subjects from Statte, the town closest to the industrial area.

For $\mathrm{Mn}$ and As the $95^{\circ}$ percentile of concentration in the whole study population is higher than the $95^{\circ}$ percentile of the range of SIVR reference values. Median concentration of As is higher in Statte than in Taranto and Laterza, while the highest concentration of $\mathrm{Mn}$ has been found in Laterza and these results deserve further investigations. Concentrations of $\mathrm{Hg}$ in the whole study population are comparable to reference values and they are higher in Statte than in Taranto and Laterza.

The overall biomonitoring data support the existence of an environmental impairment by heavy metals in the area of Taranto and mostly in the municipality of Statte. This condition can be related to the presence of industrial plants, and in particular of a large integrated steel cycle factory in the area, even if the concentration of $\mathrm{Mn}$, that could be considered a marker of steel factory emissions has been found to be higher in Laterza (the "blank" site) than in Statte and Taranto. Occupational exposures could have determined these findings and further investigations are necessary.

We observed statistically significant differences in urinary excretion of arsenic (iAs+MMA+DMA) in subjects which consumed shellfish within two days prior to the collection of urinary samples. These results confirms the suggestions of other authorative studies to recommended arsenic exposed workers to abstain from eating sea food in the 1-2 days prior to the collection of urinary samples to determine the levels of arsenic.

\section{Acknowledgements}

The authors thank the General Practitioners who participated to the study (Dr Basile, Dr Carone, Dr Catucci, Dr Colucci, Dr De Sabato, Dr Dell'Aquila, Dr Guarino, Dr Mancino, Dr Ostillio, Dr Perrone, Dr Poretti, Dr Zizza) and Dr Giovanni Caputi of the Department of Prevention - Taranto Health Local Organization, who collected biological samples in Laterza.

\section{References}

World Health Organization (WHO). Annual Report of Environment and Health 1995. Geneva; OMS; 1995

International Agency for Research on Cancer (IARC). IARC Monographs on the Evaluation of the Carcinogenic Risk of Chemicals to Humans. Some metals and metallic compounds. 23. Lyon; Iarc; 1980. Pp 39-143

IARC. IARC Monographs on the Evaluation of the Carcinogenic Risk of Chemicals to Humans: Chromium and chromium compounds. 49 Lyon; IARC; 1990

World Health Organization (WHO). Arsenic and Arsenic Compounds. Environmental Health Criteria. 224. Geneva; WHO; 2001

Vimercati L, Carrus A, Assennato G et al. A study of factors influencing urinary arsenic excretion in exposed workers. Int. J. Environ. Health Res. 2009; 19(5): 369-377

Società Italiana per i valori di riferimento. $2^{\circ}$ lista dei valori di riferimento per elementi metallici, composti organici e loro metaboliti. $2^{\circ}$ Ed rivista e corretta. Pavia; SIVR; 2005 